applying for jobs in catering as a result of his experience. Student quote 'I really enjoy working in the kitchen and have been cutting up vegetables and making cakes. The bit I enjoy most though is how we all help each other in the kitchen'. Staff have reported they were happy with the job coach's support which meant their own workload did not increase as a result of the placement.

Conclusion Students with LD can successfully integrate into work placements with the right level of support. Further placements are being considered in the housekeeping and laundry teams.

\section{P-261 THROWN IN AT THE DEEP END - SCHOOL STUDENTS EXPERIENCES ON A SIX-MONTH INPATIENT WORK PLACEMENT}

Tricia Wilcocks, Sue Marshall. ellenor Gravesend, UK

10.1136/bmjspcare-2017-hospice.286

Background Healthcare providers need to reach out to school students to attract entrants (NHS England, 2014), to bridge the growing gap between rapidly increasing demand and the shortfall in workforce supply (NHS Improvement, 2016). Student career choices need to be influenced as early as possible (National Careers Service) through diverse and positive experiences in order to improve recruitment and retention (NHS England, 2014). The quality of work experience offered in hospices varies widely (Barnard, 2016) with some hospices daring to invite school students to directly experience patient care in a supportive manner.

Aim To provide school students with direct access to patient care in a supportive environment.

Method School students aged 17+were invited to undertake a supported six- month work experience placement on a hospice inpatient ward, gaining a care certificate. Student feedback, plus pre- and post- placement questionnaires were evaluated.

Results 24 placements offered over 12 months to students from a range of academic ability. Ten completed; two left for personal reasons; twelve are currently on placement: 22 currently plan to work in care. All students embraced opportunities to learn, surprising staff with their initiative, resilience and willingness to care. Students provided assistance with personal care, feeding patients, emptying catheter bags. They were exposed to death, coping remarkably well with the emotional aspect, utilising support of review meetings to share their feelings. A wealth of qualitative was collected demonstrating overall positive experiences:

- 'I used images on Ipad to understand he wanted jelly and soft pears. He was ecstatic, and gave a thumbs up.'

- Commenting on a patient photo: 'Nice to see the person behind the illness.'

- After witnessing a death, one student told her grandparent, 'You'll be in safe hands Nan, don't worry.'

- All recognised the experience helped them to appreciate life even more.

Conclusion Valuable life skills, communication techniques and insight were gained by students.
P-262 LEADING LEARNERS - DEVELOPING A FORMAL EDUCATION PROGRAMME FOR HOSPICE CARE STAFF

Jasmine Lee, Louise Henderson, Jacqui Ray, Wendy Green, Angela Pymm. North London Hospice, London, UK

\subsection{6/bmjspcare-2017-hospice.287}

Background Historically the delivery of an education programme for inpatient nursing staff has been challenging. Particular challenges are:

1. Resourcing an education programme with leadership and teachers

2. Facilitating teaching given the clinical demands in a busy inpatient unit.

We adopted a new multi-disciplinary team joint approach with a doctor and nurse team, education team and nurse managers to run a teaching programme.

Aims - To evaluate current learning practices and teaching interest

- To develop and run a teaching programme

- To evaluate teaching with a view to creating a sustainable programme which can function against the challenges of the inpatient unit.

Methods Staff surveys were used to review current learning practice and attitudes. The team designed and delivered a weekly programme trialled over two months with pre- and post-evaluation. Five sessions have happened to date with individual session feedback.

Results In pre-programme assessment 20 staff surveys demonstrated:

- Low attendance to formal training with most attending no sessions in the last month (no sessions=63.2\%)

- All interested in attending teaching

- With $40 \%$ willing themselves to teach.

Individual session feedback demonstrates good attendance and all rated 'very good' or 'excellent'. We will additionally be presenting follow-up data at two months.

Conclusions Results demonstrate strong learning interest and some interest in teacher development. To date there is good attendance and highly positive feedback. We propose that central to its success is our team approach with dedicated nursing leadership, increasing the teaching profile, e.g., with certificates, and co-ordinators managing staff allocation between teaching and clinical duties. Lessons learnt are vitally important to help other hospices adopt successful strategies to run teaching programmes when faced with a demanding clinical environment. We will now work towards running a sustainable programme and to develop staff as teachers and learning leaders themselves.

\section{P-263 ENHANCING THE RECOGNITION OF PALLIATIVE CARE EDUCATION FOR DISTRICT NURSES - 'WALKING SIDE BY SIDE'- A PROGRAMME OF ENGAGEMENT BETWEEN HOSPICE AND COMMUNITY}

Nicola Parkes, Helen Moran, Sarah Roberts, Julie Huttley. Trinity Hospice Blackpool, UK

10.1136/bmjspcare-2017-hospice.288 